\title{
Five new species of Minettia (Minettiella) (Diptera, Lauxaniidae) from China
}

\author{
Li Shi', Ding Yang² \\ I College of Agronomy, Inner Mongolia Agricultural University, Hohhot, Nei Mongol 010019, China \\ 2 Department of Entomology, China Agricultural University, Beijing 100193, China \\ Corresponding author: Li Shi (lishiagromyzid@gmail.com; lirui2003@imau.edu.cn)
}

$\frac{\text { Academic editor: } R \text {. Meier | Received 29 April } 2014 \text { | Accepted 6 October } 2014 \mid \text { Published } 22 \text { October } 2014}{\text { http://zoobank.org/3C37DA91-ACC0-4DC5-8983-C31D2C060766 }}$

Citation: Shi L, Yang D (2014) Five new species of Minettia (Minettiella) (Diptera, Lauxaniidae) from China. ZooKeys 449: 81-103. doi: 10.3897/zookeys.449.7807

\begin{abstract}
Five species of Minettia Robineau-Desvoidy, 1830 from the South of China are described as new to science: Minettia (Minettiella) bawanglingensis sp. n., M. (Minettiella) clavata sp. n., M. (Minettiella) plurifurcata sp. n., M. (Minettiella) spinosa sp. n. and M. (Minettiella) tianmushanensis sp. n. Minettiella elbergi Shatalkin, 1996 and Minettia japonica Sasakawa, 1995 are treated as junior synonyms of M. (Minettiella) dolabriforma (Sasakawa \& Kozánek, 1995). A key to five subgenera of Minettia and eleven species of Minettia (Minettiella) is presented.
\end{abstract}

\section{Keywords}

Minettiella, synonym, female terminalia, Oriental region

\section{Introduction}

The subgenus Minettiella Malloch, 1929, of the genus Minettia Robineau-Desvoidy, 1830, was erected for the type species Lauxania atratula Meijere, 1910, being glossy black, and having immaculate wings, yellow halteres, a katepisternum with a discal katepisternal seta, pubescent aristae, shining frons, a flat face, and mesonotum with $0-1+2-3$ dorsocentral setae and $0-1+2-4$ acrostichal setae, and most species having one to three pairs of strong acrostichal setae (Malloch 1929; Stuckenberg 1971). 
Actually, all species have pruinosity on the mesonotum and abdomen (only the frons is shining black), so the so-called "glossy" black habitus is not correct.

Shatalkin (1996) had elevated the subgenus Minettiella to the genus level when he described Minettiella elbergi Shatalkin, 1996. Shatalkin (2000) discussed that its having genus rank was based on the specialized male genitalia and the above-mentioned diagnosis, and noted that the described species Minettiella acrostichalis (Sasakawa \& Kozánek, 1995) was possibly a synonym of Minettiella coracina Shatalkin, 1993, and two described species Minettiella elbergi and Minettia japonica (Sasakawa, 1995) were possibly synonyms of Minettiella dolabriforma (Sasakawa \& Kozánek, 1995) (Shatalkin 2000). We examined the male genitalia of some specimens from five subgenera of Minettia and found that the diversity of the male genitalia (that is, there are lots of many different forms among the species) exists in the three subgenera Minettia, Minettiella and Plesiominettia Shatalkin, 2000, which is more diversity of male genitalia than that in two subgenera Frendelia (Collin, 1948) and Scotominettia (Shatalkin, 2008) based on many examined specimens of five genera from the Palaearctic and Oriental regions. The diversity of the male genitalia in Minettiella is the same as that in Minettia and Plesiominettia. So we reject Shatalkin's elevation of the subgenus Minettiella to the genus level and consider Minettiella as a subgenus Minettiella. Moreover, we compared the male genitalia M. (Minettiella) elbergi and M. (Minettiella) japonica and determined them to be junior synonyms of $M$. (Minettiella) dolabriforma. The color of the mid and hind tibiae and the ratio of height and length of the 1st flagellomere in $M$. (Minettiella) coracina Shatalkin are distinctly different from that in M. (Minettiella) acrostichalis (Sasakawa \& Kozánek, 1995), so the species M. (Minettiella) coracina Shatalkin is considered to be a valid species.

The type specimen of M. (Minettiella) atrata (Meijere, 1910) was recorded in Jong (2000) as missing the male genitalia, but fortunately the description and diagnosis is adequate to separate it from other species.

In total, there are eleven known species of the subgenus Minettiella with six currently found in China (see Appendix for species checklist).

\section{Materials and methods}

The general terminology follows Gaimari and Silva (2010). Genitalia preparations were made by removing and macerating the apical portion of the abdomen in cold saturated $\mathrm{NaOH}$ for 6 hours. After examination, they were transferred to glycerine for examination and stored in a microvial on the pin below the specimen. Specimens examined were deposited in China Agricultural University, Beijing, China (CAUC).

The following abbreviations are used: $a$-anterior seta(e), $a c r-$ acrostichal seta(e), $a d$-anterior dorsal seta(e), app-apical posterior seta(e), $a p v$-apical ventral seta(e), $a v$-anterior ventral seta(e), $d c$-dorsocentral seta(e), $i a$-intra alar, kepst-katepisternal seta(e), oc-ocellar seta(e), or-fronto-orbital seta(e), $p$-posterior seta(e), $p d$-posterior dorsal seta(e), prsc-prescutellar seta(e), $p v$-posterior ventral seta(e). 


\section{Taxonomy}

\section{Species descriptions}

Unless otherwise specified, the following seven species described below are characterized as follows: Head, thorax and abdomen black. Frons wider than long and parallel-sided. Face and parafacial flat with dense whitish gray pruinosity. Ocellar triangle black; $o c$ developed, shorter than anterior $o r$, anterior or reclinate, shorter than posterior or. Arista black with yellow at base. Scutellum black, with brown grayish pruinosity. All femora black or blackish brown. Wing slightly yellow, hyaline. Halter yellow.

\section{Minettia (Minettiella) atratula (Meijere, 1924)}

Figs 1-5, 31-32

Lauxania atratula Meijere, 1924: 49. Type locality: Indonesia (Sumatra). Minettia (Minettiella) atratula: Malloch 1929: 26. Shewell 1977: 190. Shatalkin 1996: 147. Jong 2000: 32.

Material examined. $2 \hat{\partial} \widehat{\partial}, 1+$ (CAUC), CHINA, Hainan: Ledong, Jianfengling National Natural Reserve, Tianchi, 800 m, 18. v. 2006, Hui Dong; $1 \overbrace{}^{\lambda}$ (CAUC), CHINA, Hainan: Ledong, Jianfengling National Natural Reserve, Tianchi, 800 m, 18. v. 2006, Gang Yao.

Diagnosis. Mesonotum $1+3 d c$, acr in 2 rows with $1+3$ long acr. Fore tibia yellowish brown with yellow at base and black at apex, mid tibia yellow and hind tibia yellow with brown at apex; fore tarsi with basitarsus yellow on basal 3/4 and tarsomeres $2-5$ brown, mid and hind tarsi with tarsomeres 1-2 dark yellow and tarsomeres 3-5 pale brown. Mid femur with $4 a$.

Redescription. MALE. Body length 3.3-3.5 mm, wing length 3.4-3.5 mm. FEMALE. Body length $3.8 \mathrm{~mm}$, wing length $3.9 \mathrm{~mm}$.

Head. Frons slightly concave with narrow yellow anterior margin. Gena about $1 / 4$ eye height. Antenna scape and pedicel yellowish brown to brown, 1st flagellomere blackish brown with yellow at base and nearly 2.3 times longer than high; arista bare. Proboscis black with dark yellow at apex. Palpus black.

Thorax with brownish gray pruinosity. Mesonotum with $1+3 d c$, acr in 2 rows with $1+3$ long acr in front of prsc and one pair of prsc as long as 1 st postsutural $d c$. Legs: fore tibia mostly yellowish brown with yellow at base and black at apex; mid tibia yellow and hind tibia yellow with brown at apex; fore tarsi with basitarsus yellow on basal 3/4 and tarsomeres 2-5 brown, mid and hind tarsi with tarsomeres 1-2 dark yellow and tarsomeres 3-5 pale brown. Fore femur with $4 p v$ and $6 p d$, fore tibia with 1 long preapical $a d$ and 1 short $a p v$. Mid femur with $4 a$ and $1 a p p$; mid tibia with 1 strong preapical $a d$ and 1 strong $a p v$. Hind femura with 1 preapical $a d$, and hind tibia with 1 weak preapical $a d$ and 1 short $a p v$. Wing with costa 


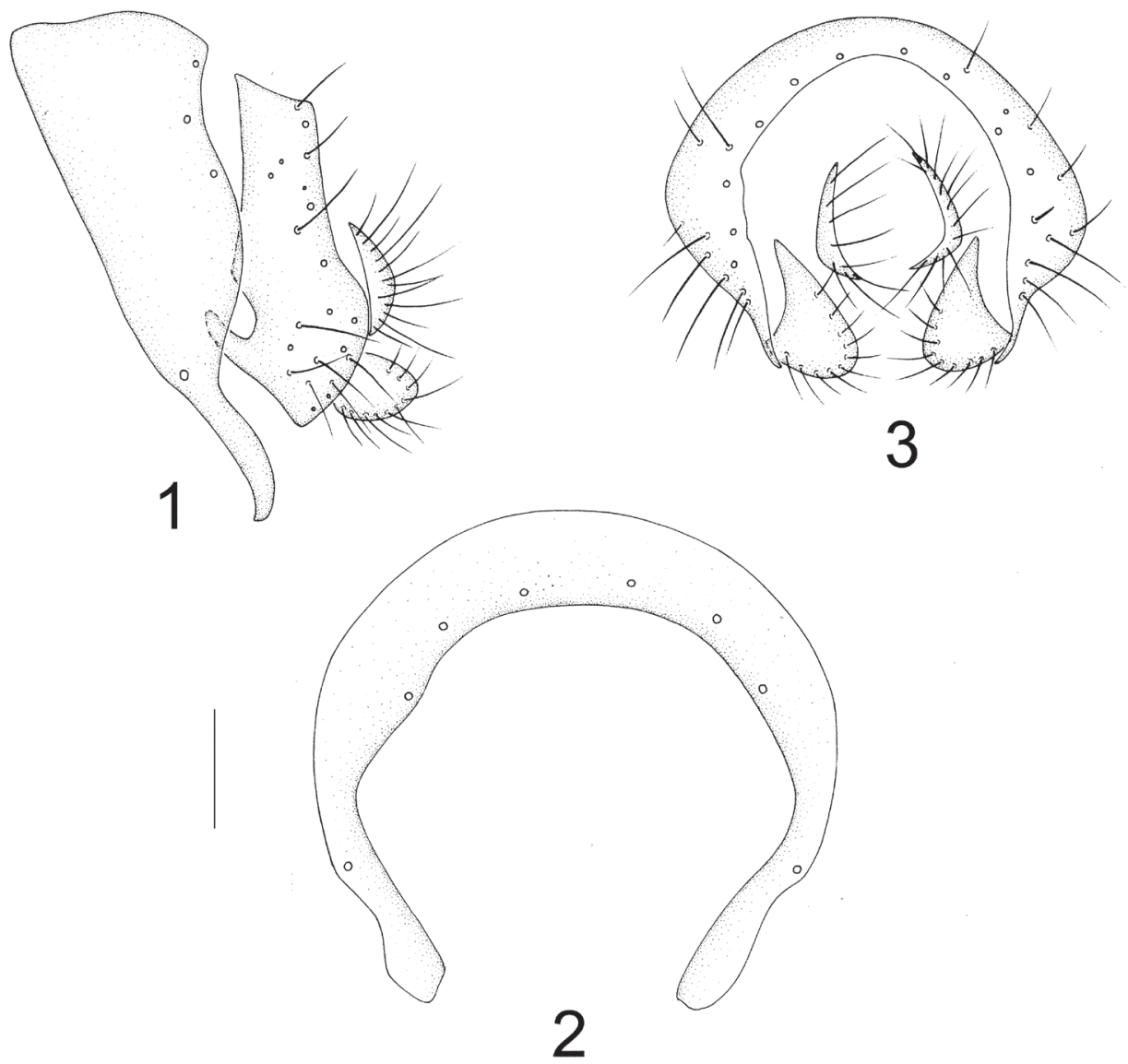

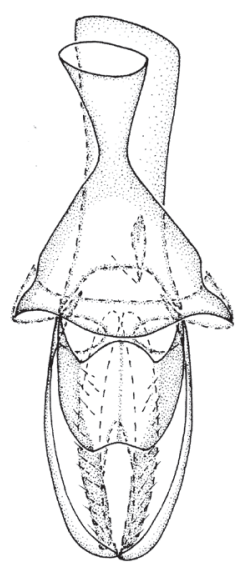

4

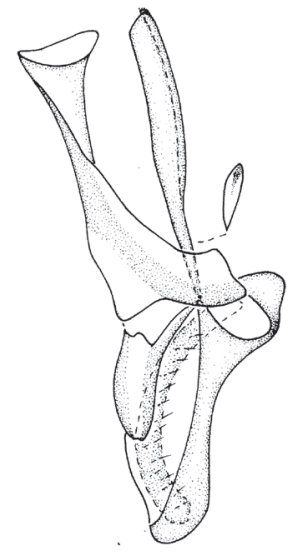

5

Figures I-5. Minettia (Minettiella) atratula (Meijere, 1924). Male. I syntergosternite and epandrium, lateral view $\mathbf{2}$ syntergosternite, anterior view $\mathbf{3}$ epandrial complex, posterior view $\mathbf{4}$ aedeagal complex, ventral view $\mathbf{5}$ aedeagal complex, lateral view. Scale bar $=0.1 \mathrm{~mm}$. 
with 2nd (between $\mathrm{R}_{1}$ and $\mathrm{R}_{2+3}$ ), 3rd (between $\mathrm{R}_{2+3}$ and $\mathrm{R}_{4+5}$ ) and 4th (between $\mathrm{R}_{4+5}$ and $\mathrm{M}_{1}$ ) sections in proportion of 6.7:1:1, $r-m$ at middle of discal cell; ultimate and penultimate sections of $\mathrm{M}_{1}$ in proportion of $1: 1.1$; ultimate section of $\mathrm{CuA}_{1}$ about $1 / 6$ of penultimate section.

Abdomen with sparse brownish gray pruinosity. Male genitalia (Figs 1-5): syntergosternite semicircular with three pairs of dorsal setulae, epandrium narrow basally and broad apically, with a deep concave on anterior ventral margin and a digitiform anterior process, triangular apically in lateral view; surstylus separated from epandrium, elliptical in lateral view but crescent-shaped in posterior view; hypandrium nearly Y-shaped; postgonite forming a complete sclerite, with a median ridge; aedeagus consisting of a pair of clavate inner sclerites with short setulae and a pair of dorsolateral concaves, rounded apically; height of aedeagal apodeme nearly as long as aedeagus and broad in ventral view. Female terminalia (Figs 31-32): sternite 8 with a brown U-shaped spot, spermathecae 2+1, elliptical.

Distribution. China (Hainan, Taiwan), Indonesia (Sumatra), Vietnam.

\section{Minettia (Minettiella) bawanglingensis sp. $\mathbf{n}$.} http://zoobank.org/2742238E-F11B-4A8C-BDEF-85B255376811

Figs 6-10, 33-34

Type material. Holotype: $\hat{\jmath}$ (CAUC), CHINA, Hainan: Changjiang, Bawangling National Natural Reserve, Dong'er station, 1000 m, 24. v. 2007, Kuiyan Zhang. Paratype: 19 (CAUC), CHINA, Hainan: as holotype.

Etymology. The new species is named after the type locality Bawangling National Natural Reserve.

Diagnosis. Arista pubescent, with longest rays about $1 / 4$ height of 1 st flagellomere. Mesonotum with $0+2 d c$, acr in 6 rows, two pairs of long $a c r$. Mid femur with $3 a$.

Description. MALE. Body length $4.4 \mathrm{~mm}$, wing length $4.2 \mathrm{~mm}$. FEMALE. Body length $4.0 \mathrm{~mm}$, wing length $3.9 \mathrm{~mm}$.

Head. Frons slightly concaved with yellow anterior margin. Gena about $1 / 6$ eye height. Antenna blackish brown, 1st flagellomere yellow at base, and 1st flagellomere nearly 1.6 times longer than high; arista pubescent, with longest rays about $1 / 4$ height of 1 st flagellomere. Proboscis black with dark yellow at apex and palpus black.

Thorax with brownish gray pruinosity. Mesonotum $0+2 d c$ (anterior $d c$ far behind transverse scutal suture), acr in 6 rows; two pairs of long acr present in front of prsc, prsc slightly shorter than 1 st post-sutural $d c$. Legs: tibia black with yellow at base, mid and hind tarsi yellow. Fore femur with $4 p v$ and $8 p d$, fore tibia with 1 short preapical $a d$ and 1 short $a p v$. Mid femur with $3 a$ and 1 app; mid tibia with 1 strong preapical $a d$ and 1 strong $a p v$. Hind femura with 1 weak preapical $a d$, hind tibia with 1 weak preapical $a d$ and 1 short $a p v$. Wing with costa with 2 nd (between $\mathrm{R}_{1}$ and $\mathrm{R}_{2+3}$ ), 3rd (between $\mathrm{R}_{2+3}$ and $\mathrm{R}_{4+5}$ ) and 4th (between $\mathrm{R}_{4+5}$ and $\mathrm{M}_{1}$ ) sections in proportion of $7: 1.3: 1 ; r-m$ beyond middle of discal cell; ultimate and penultimate 

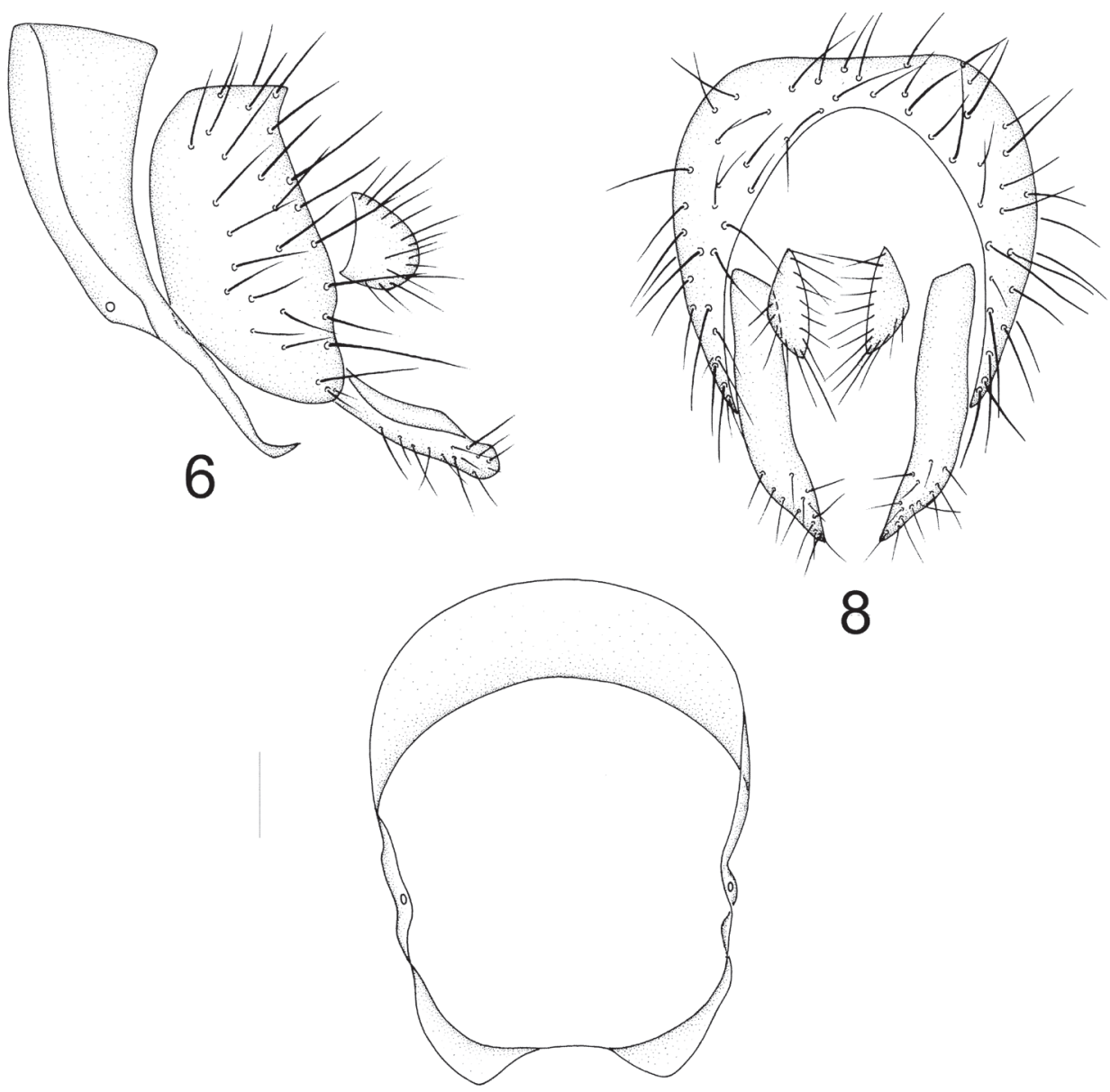

8

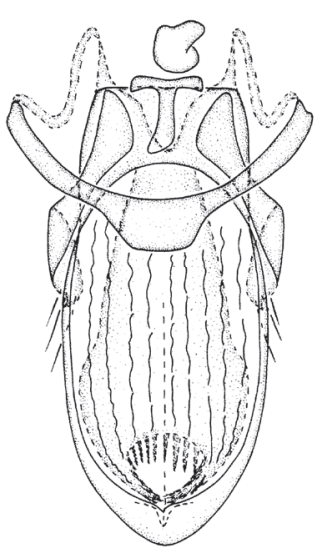

9

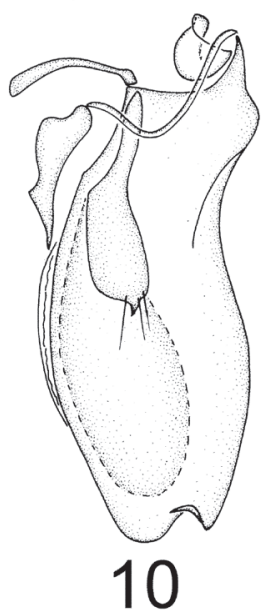

Figures 6-10. Minettia (Minettiella) bawanglingensis sp. n. Male. 6 syntergosternite and epandrium, lateral view $\mathbf{7}$ syntergosternite, anterior view $\mathbf{8}$ epandrial complex, posterior view $\mathbf{9}$ aedeagal complex, ventral view 10 aedeagal complex, lateral view. Scale bar $=0.1 \mathrm{~mm}$. 
sections of $\mathrm{M}_{1}$ in proportion of $1: 1$; ultimate section of $\mathrm{CuA}_{1}$ about $1 / 7$ of penultimate section.

Abdomen with sparse brownish gray pruinosity. Male genitalia (Figs 6-10): syntergosternite circular with a weak ventral bridge, epandrium with a tiny subapical concave, surstylus separated from epandrium, consisting of a long claviform process with setulae in lateral view and with a long triangular process in posterior view; hypandrium slender, projecting medially and nearly V-shaped; postgonite contorting, consisting of an acute triangular apical process and three apical setae; aedeagus columnar, truncate basally and blunt rounded apically, consisting of a triangular dorsal process subapically in lateral view and a black bottle-shaped inner process with an elliptical incision and many spiculate processes in ventral view; aedeagal apodeme narrow and short, projecting forwards, nearly right angle between hypandrium and aedeagus. Female terminalia (Figs 33-34): sternite 7 trapeziform with long setae on posterior margin, sternite 8 semicircular with three pairs of long setae on posterior margin and sternite 9 with a groove; spermathecae $2+1$, round and all stems leading to the three spermathecae narrow apically.

Remarks. The new species is very similar to M. (Minettiella) dolabriforma from the Palaearctic region in the following characteristics: mesonotum $0+2 d c$, legs black with base of tibia yellow and mid and hind tarsi yellow, but it can be separated from the latter in the following characteristics: surstylus consisting of a long claviform process with setulae in lateral view and with a long triangular process in posterior view; hypandrium projecting medially and nearly V-shaped; aedeagus consisting of a triangular dorsal process subapically in lateral view and a black, bottle-shaped inner process with an elliptical incision and many speculate processes in ventral view. In M. (Minettiella) dolabriforma, the surstylus has a spatulate process, narrow ventrally and pointed at apex in lateral view; the hypandrium is U-shaped; the aedeagus is pointed dorsoapically with a lobate dorsal process in lateral view, and is spinulose and brownish-striated on the median ventral membrane in ventral view (Sasakawa 1995). The new species is also similar to $M$. (Minettiella) atrata from Indonesia (Java) in mesonotum with $0+2$ $d c$ and a pair of long acr present in front of prsc, but it can be separated from the latter in the arista having microscopic setulae, and the mid and hind tarsi being yellow. In M. (Minettiella) atrata, the arista is short plumose and only the hind tarsi are yellow (Meijere 1910).

Distribution. China (Hainan).

\section{Minettia (Minettiella) clavata sp. n.}

http://zoobank.org/A727B963-F589-4B19-910C-FC9F3D0BE476

Figs 11-15, 35-36

Type material. Holotype: $\widehat{\gamma}$ (CAUC), CHINA, Hubei: Shennongjia National Natural Reserve, Pingqian, 1650 m, 26. VII. 2007, Qifei Liu. Paratypes: $4 \hat{\jmath} \widehat{\jmath}, 1$ 우 (CAUC), CHINA, Hubei: Shennongiia National Natural Reserve, Pingqian, 1650 m, 27. vii. 

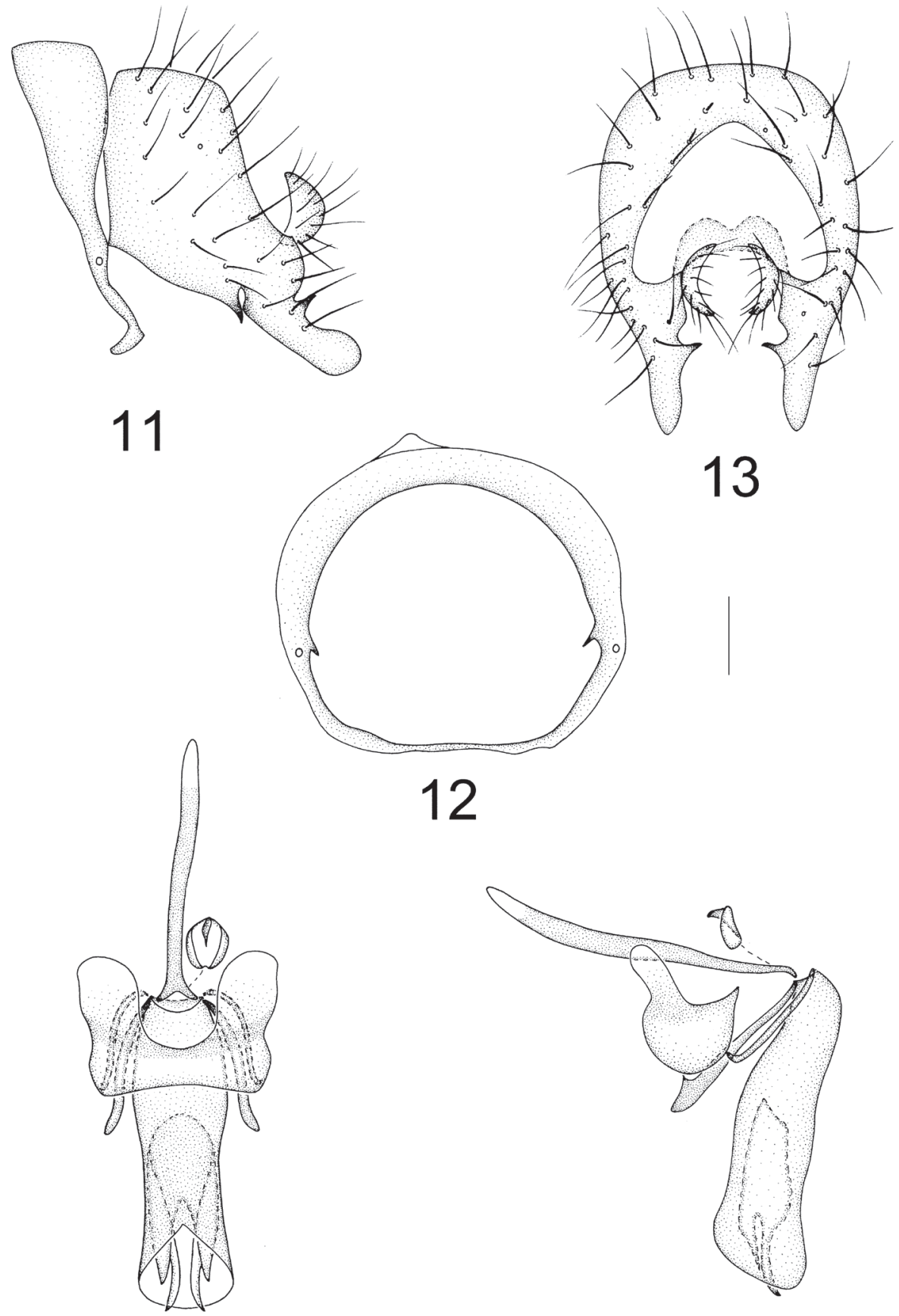

13
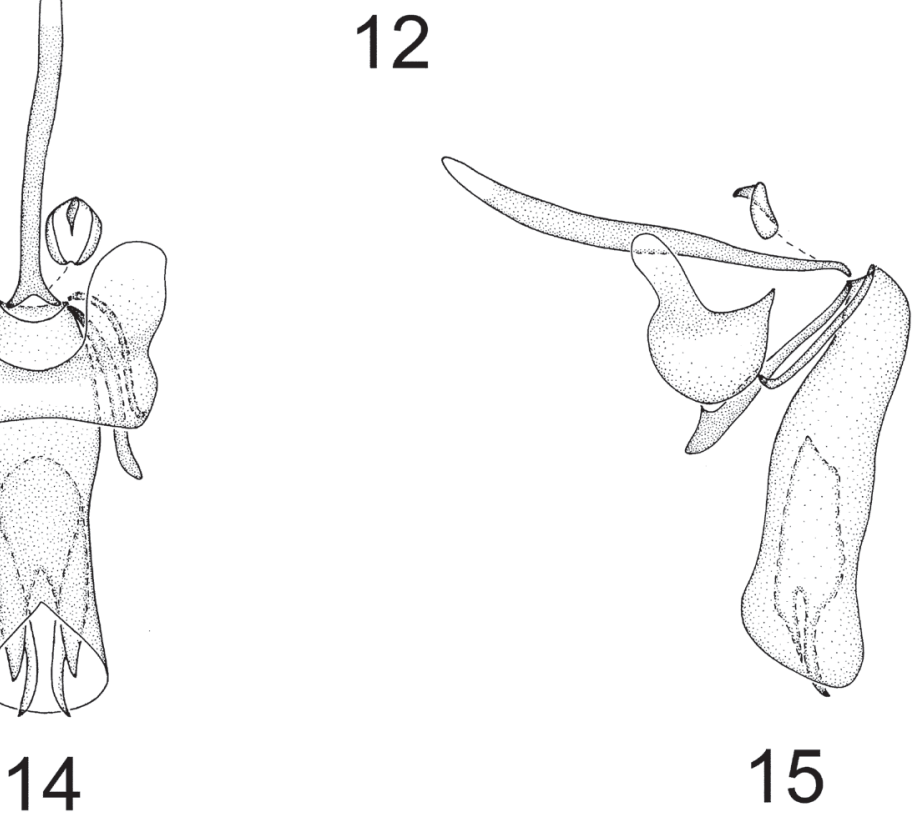

Figures II-I5. Minettia (Minettiella) clavata sp. n. Male. II syntergosternite and epandrium, lateral view $\mathbf{I} \mathbf{2}$ syntergosternite, anterior view $\mathbf{I}$ epandrial complex, posterior view $\mathbf{I} \mathbf{4}$ aedeagal complex, ventral view $\mathbf{I} \mathbf{5}$ aedeagal complex, lateral view. Scale bar $=0.1 \mathrm{~mm}$. 
2007, Qifei Liu; 4 + (CAUC), CHINA, Hubei: Shennongjia National Natural Reserve, Pingqian, $1650 \mathrm{~m}, 25$. vii. 2007, Qifei Liu.

Etymology. Latin, clavata, meaning clavate; referring to the club-like surstylus; a feminine adjective.

Diagnosis. Antenna yellow with 1st flagellomere brown on apical 2/3; arista plumose, with longest rays slightly shorter than height of 1st flagellomere. Mesonotum $0+3 d c$, anterior $d c$ weak, hair-like; acr in 6 rows. All tibiae black with pale yellow at base; fore tarsi black, mid and hind tarsi dark yellow. Mid femur with $5 a$.

Description. MALE. Body length 2.9-3.7 mm, wing length 3.2-3.8 mm. FEMALE. Body length 3.0-3.3 mm, wing length 3.3-3.7 mm.

Head. Face slightly shining. Frons with yellow anterior margin. Gena about 1/6 eye height. Antenna yellow with brown on apical $2 / 3$ of 1 st flagellomere, 1 st flagellomere nearly 1.7 times longer than high; arista plumose, with longest rays slightly shorter than height of 1 st flagellomere. A blackish brown rectangular spot present between eye and base of antenna. Proboscis and palpus black.

Thorax with brownish gray pruinosity. Mesonotum $0+3 d c$ (anterior $d c$ weak, hair-like, far behind transverse scutal suture), acr in 6 rows; prsc longer than 1 st post-sutural $d c$; anepisternum with setulae on lower margin. Legs: all tibiae black with pale yellow at base; fore tarsi black, mid and hind tarsi dark yellow. Fore femur with $4 p v$ and $6 p d$, fore tibia with 1 short preapical $a d$ and 1 short $a p v$. Mid femur with $5 a$ and $1 a p p$; mid tibia with 1 strong preapical $a d$ and 1 strong $a p v$. Hind tibia with 1 weak preapical $a d$ and 1 short $a p v$. Wing with costa with 2 nd (between $\mathrm{R}_{1}$ and $\mathrm{R}_{2+3}$ ), 3rd (between $\mathrm{R}_{2+3}$ and $\mathrm{R}_{4+5}$ ) and 4th (between $\mathrm{R}_{4+5}$ and $\mathrm{M}_{1}$ ) sections in proportion of 4:1.7:1; $r-m$ at middle of discal cell; ultimate and penultimate sections of $M_{1}$ in proportion of 1:1.1; ultimate section of $\mathrm{CuA}_{1}$ about $1 / 5$ of penultimate section.

Abdomen shining. Male genitalia (Figs 11-15): syntergosternite circular with an inner tooth near spiracle, epandrium nearly rectangular; surstylus fused with epandrium, clavate with a triangular basal process, a projecting apical process, a small acute ventroapical process and a tiny incision in lateral view; hypandrium nearly U-shaped, hypandrial apodeme distinct; postgonite slender, broad apically in lateral view; aedeagus columnar and rounded apically, with a slight incision; aedeagal apodeme long, slightly shorter than aedeagus. Female terminalia (Figs 35-36): sternite 7 trapeziform, furcating apically with long setae; sternite 8 pale yellow, nearly columnar with a small apical incision; spermathecae $2+1$, round.

Remarks. The new species is very similar to M. (Minettiella) plurifurcata sp. n. (see discussion under M. (Minettiella) plurifurcata sp. n.) from China (Hubei). This new species is also similar to M. (Minettiella) atrata from Indonesia (Java) in having the arista short plumose and the mesonotum with acr 6 rows, and without other strong acr in front of strong prsc, but it can be separated from the latter by the mid and hind tarsi being yellow. In M. (Minettiella) atrata, only the hind tarsi are yellow (Meijere 1910; Malloch 1929).

Distribution. China (Hubei). 


\section{Minettia (Minettiella) plurifurcata sp. $\mathrm{n}$.}

http://zoobank.org/CAF5D321-6C62-41A3-A45F-B3F1FE218BAE

Figs 16-20

Type material. Holotype: $\widehat{\partial}$ (CAUC), CHINA, Hubei: Shennongjia National Natural Reserve, Pingqian, 1650 m, 26. vii. 2007, Qifei Liu.

Etymology. Latin, pluri-, meaning many, and furcata, meaning forked; referring to the aedeagus with forked and acute processes in different lengths; a feminine adjective.

Diagnosis. Arista plumose, with longest rays slightly shorter than height of 1 st flagellomere. Thorax with whitish gray pruinosity, sparse on anterior $1 / 2$ and dense on posterior $1 / 2$. Mesonotum $0+3 d c$ (anterior $d c$ far behind transverse scutal suture), acr in 6 rows. All tibiae pale yellow at base; fore tarsi black, mid and hind tarsi dark yellow. Mid femur with $4 a$.

Description. MALE. Body length $3.7 \mathrm{~mm}$, wing legth $4.2 \mathrm{~mm}$.

Head. Frons with yellow anterior margin. Gena about 1/7 eye height. Antenna yellow with brown on apical $2 / 3$ of 1 st flagellomere, 1 st flagellomere nearly 2.0 times longer than high; arista plumose, with longest rays slightly shorter than height of 1 st flagellomere. A black round spot present between eye and base of antenna. Proboscis and palpus black.

Thorax with whitish gray pruinosity, sparse on anterior $1 / 2$ and dense on posterior $1 / 2$. Mesonotum $0+3 d c$ (anterior $d c$ far behind transverse scutal suture), acr in 6 rows; prsc as long as 1st postsutural $d c$; anepisternum with setulae on lower margin. Legs: tibia black with pale yellow at base; fore tarsi black, mid and hind tarsi dark yellow. Fore femur with $5 p v$ and $8 p d$, fore tibia with 1 short preapical $a d$ and 1 short $a p v$. Mid femur with $4 a$ and $1 a p p$; mid tibia with 1 strong preapical $a d$ and 1 strong $a p v$. Hind tibia with 1 weak preapical $a d$ and 1 short $a p v$. Wing with costa with 2 nd (between $\mathrm{R}_{1}$ and $\mathrm{R}_{2+3}$ ), 3rd (between $\mathrm{R}_{2+3}$ and $\mathrm{R}_{4+5}$ ) and 4th (between $\mathrm{R}_{4+5}$ and $\mathrm{M}_{1}$ ) sections in proportion of 5.2:4:1; $r-m$ at middle of discal cell; ultimate and penultimate sections of $\mathrm{M}_{1}$ in proportion of 1:1.2; ultimate section of $\mathrm{CuA}_{1}$ about $1 / 5$ of penultimate section.

Abdomen with sparse whitish gray pruinosity. Male genitalia (Figs 16-20): syntergosternite circular with dorsal setulae, epandrium with a wide median incision on dorsal margin in lateral view; surstylus short subuliform and originating from inner side of epandrium in lateral view and convergent apically in posterior view; hypandrium nearly W-shaped; postgonite slender, slightly curved with 2-3 short apical setulae; aedeagus slender, columnar and rounded apically, with furcated acute processes in different length; aedeagal apodeme short, as long as $1 / 3$ length of aedeagus.

FEMALE. Unknown.

Remarks. The new species is very similar to $M$. (Minettiella) clavata sp. n. from China (Hubei) in the following characteristics: acr in 6 rows; all femora black and tibiae black with pale yellow at base; fore tarsi black, mid and hind tarsi dark yellow; wing yellow at base, but it can be separated from the latter in the following characteristics: the mesonotum having whitish gray pruinosity, sparse on anterior half and dense on posterior half, and $0+3 d c$, anterior $d c$ strong; the surstylus being long triangular and 

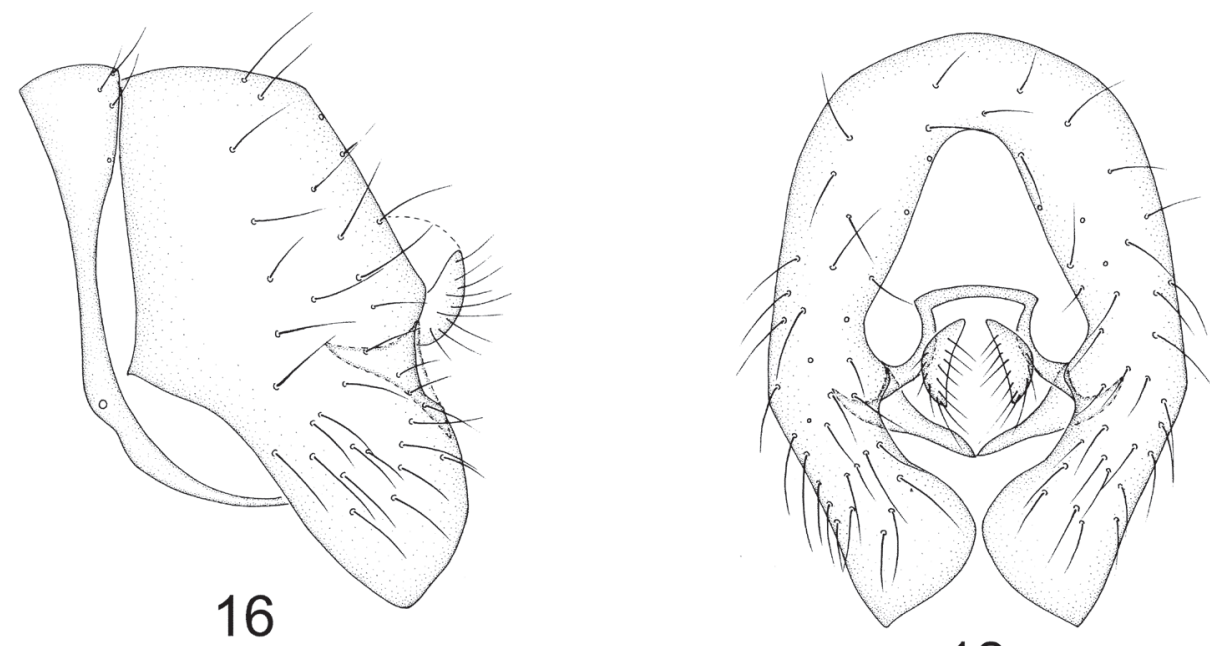

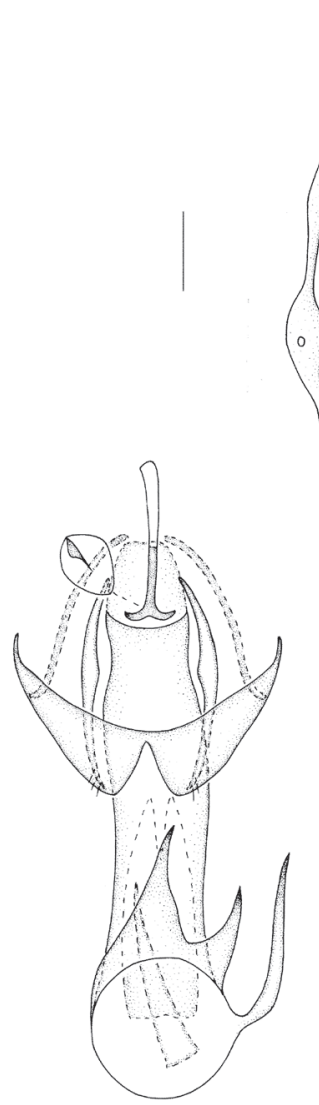

19

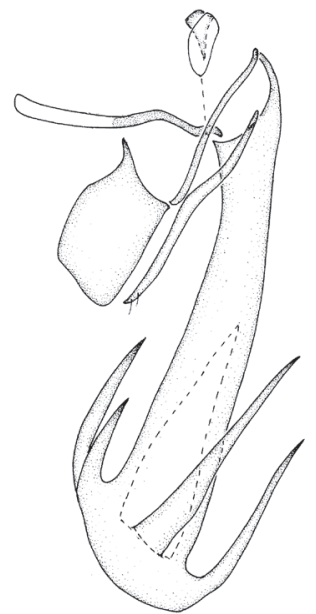

20

Figures 16-20. Minettia (Minettiella) plurifurcata sp. n. Male. 16 syntergosternite and epandrium, lateral view $\mathbf{I} \mathbf{7}$ syntergosternite, anterior view $\mathbf{I} 8$ epandrial complex, posterior view $\mathbf{1} \mathbf{9}$ aedeagal complex, ventral view 20 aedeagal complex, lateral view. Scale bar $=0.1 \mathrm{~mm}$. 
originating from the inner side of the epandrium. In M. (Minettiella) clavata, the mesonotum has $0+3 d c$ with anterior $d c$ weak, hair-like; the epandrium is nearly rectangular; the surstylus is fused with the epandrium, and claviform with a triangular basal process a projecting apical process, a small acute ventroapical process and a tiny incision in lateral view.

Distribution. China (Hubei).

\section{Minettia (Minettiella) sasakawai Shi, Wang \& Yang, 2011}

Sapromyza (Sapromyza) acrostichalis Sasakawa, 2001: 50. Type locality: Vietnam.

Minettia (Minettiella) sasakawai nom. n. (comb. n. preoccupied by acrostichalis (Sasakawa \& Kozánek, 1995), a new name as a replacement of acrostichalis Sasakawa, 2001) Minettia (Minettiella) sasakawai Shi, Wang \& Yang, 2011: 80 (with figures).

Material examined. CHINA, Hainan (CAUC) $5 \hat{\jmath} \widehat{\partial}$, Ledong, Jianfengling National Natural Reserve, Plant garden, 800 m, 8. v. 2008, Qifei Liu; 1 Ô, Ledong, Jianfengling National Natural Reserve, Sanfenqu, 800 m, 8. v. 2008, Qifei Liu; 2 ふ઼, Ledong, Jianfengling National Natural Reserve, Plant garden, 800 m, 18. v. 2006, Gang Yao; 3 $\widehat{\widehat{\partial}} \widehat{\jmath}, 2$ 우, Changiiang, Bawangling National Natural Reserve, Donger station, 1000 m, 24-25. v. 2007, Junhua Zhang; 1 त, Baisha, Yinggeling National Natural Re-

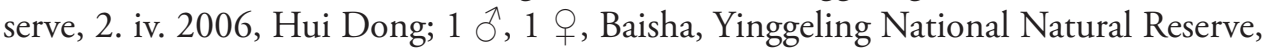
Hongmao village, 430 m, 21-22. v. 2007, Kuiyan Zhang; 1 đે. Baisha, Yinggeling National Natural Reserve, Hongmao village, 430 m, 21-22. v. 2007, Junhua Zhang; 1 ㅇ, Baisha, Yinggeling National Natural Reserve, Hongmao village, 430 m, 21. v. 2007, Yongjie Wang.

Diagnosis. Body black with brownish gray. Face and parafacial black flat with dense whitish gray pruinosity. Antennal 1st flagellomere blackish brown except yellow at base. Mesonotum $0+2 d c$ (anterior $d c$ far behind transverse scutal suture), acr in 4 rows; a pair of long acr present in front of prsc. Legs mostly black except fore basal tarsus dark yellow on basal 3/4 and mid and hind tarsi dark yellow. Basal part of wing yellow. Abdomen shining black with sparse brownish gray pruinosity.

Redescription. MALE. Body length 3.2-4.1 mm, wing length 3.4-4.4 mm. FEMALE. Body length 3.4-3.7 mm, wing length 3.6-3.9 mm.

Head black. Frons shining black except yellow, slightly concaved anterior margin; $o c$ slightly longer than anterior $o r$. Gena about $1 / 6$ height of eye. Antenna scape and pedicel yellowish brown, 1st flagellomere blackish brown except yellow on basal part, 1 st flagellomere nearly 1.8 times longer than high; arista with microscopic setulae. Proboscis black except yellow at apex; palpus black.

Thorax black with brownish gray pruinosity. Mesonotum with $0+2 d c$ (anterior $d c$ far behind transverse scutal suture), acr in 4 rows; a pair of long acr present in front of prsc, prsc nearly as long as 1 st postsutural $d c ; 1 i a, 1$ kepst. Legs with fore basal tarsus 
dark yellow on basal $3 / 4$ and mid and hind tarsi dark yellow. Fore femur with $5 p v, 8$ $p d$, fore tibia with 1 long preapical $a d$ and 1 short $a p v$. Mid femur with $4 a$ and $1 a p p$; mid tibia with 1 strong preapical $a d, 1$ strong $a p v$. Hind femura with 1 weak preapical $a d$, hind tibia with 1 weak preapical $a d$ and 1 short $a p v$. Wing: costa with 2 nd (between $\mathrm{R}_{1}$ and $\mathrm{R}_{2+3}$ ), 3rd (between $\mathrm{R}_{2+3}$ and $\mathrm{R}_{4+5}$ ) and 4th (between $\mathrm{R}_{4+5}$ and $\mathrm{M}_{1}$ ) sections in proportion of $6: 1.7: 1 ; r-m$ at middle of discal cell; ultimate and penultimate sections of $\mathrm{M}_{1}$ in proportion of $1: 1.1$; ultimate section of $\mathrm{CuA}_{1}$ about $1 / 6$ of penultimate section.

Abdomen black with sparse brownish gray pruinosity. Male genitalia: protandrium semicircular (with a weak ventral bridge in a few specimens), narrow under spiracle; epandrium slender, with dorsal setae in lateral view; surstylus separated from epandrium, slender, narrow apically with a falcate apical process in lateral view; hypandrium very narrow at middle and broad on two lateral sides; postgonite columnar with two long setae; aedeagus acute apically with a tiny incision in ventral view but oblique truncate apically in lateral view; aedeagal apodeme nearly as long as aedeagus. Female terminalia: tergite 6 with a pair of long dorsal setae on posterior margin; spermathecae $2+1$, round.

Distribution. China (Hainan), Vietnam.

Remarks. The species is very similar to Minettia (Minettiella) tianmushanensis sp. $\mathrm{n}$. from Zhejiang (see M. (Minettiella) tianmushanensis sp. n.). The new species is also similar to Minettia (Minettiella) atrata from Indonesia (Java) in the following characters: mesonotum with $0+2 d c$ and a pair of long acr present in front of prsc, but it can be separated from the latter by the arista having microscopic setulae, the mesonotum having the acr in 4 rows, and the legs mostly black except the fore basal tarsus dark yellow on basal 3/4 and the mid and hind tarsi dark yellow. In Minettia (Minettiella) atrata, the arista is short plumose, the mesonotum has acr in 6 rows and the hind tarsi is yellow (Meijere 1910).

\section{Minettia (Minettiella) spinosa sp. n.} http://zoobank.org/0AB04092-C12C-4688-9F84-A5B564C66D9C Figs 21-25, 39-40

Type material. Holotype $\widehat{\partial}$ (CAUC), CHINA, Hubei: Shennongjia National Natural

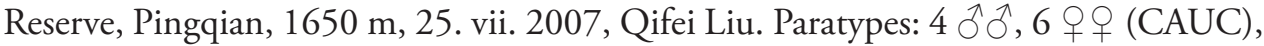

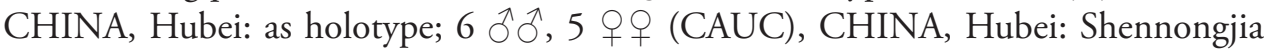
National Natural Reserve, Pingqian, 1650 m, 27. vii. 2007, Qifei Liu.

Etymology. Latin, spinosa, meaning spinose or with spinules; referring to the aedeagus with many short ventral spinules; a feminine adjective.

Diagnosis. Face with a yellow triangular median spot or only slightly yellow in center of face. Arista with microscopic setulae, longest rays shorter than $1 / 3$ height of 1 st flagellomere. All tibiae dark yellow and tarsi dark yellow with tarsomeres 3-5 pale brown (apex of fore tibia pale brown in a few specimens); mid femur with $3 a$. Wing black at base. 

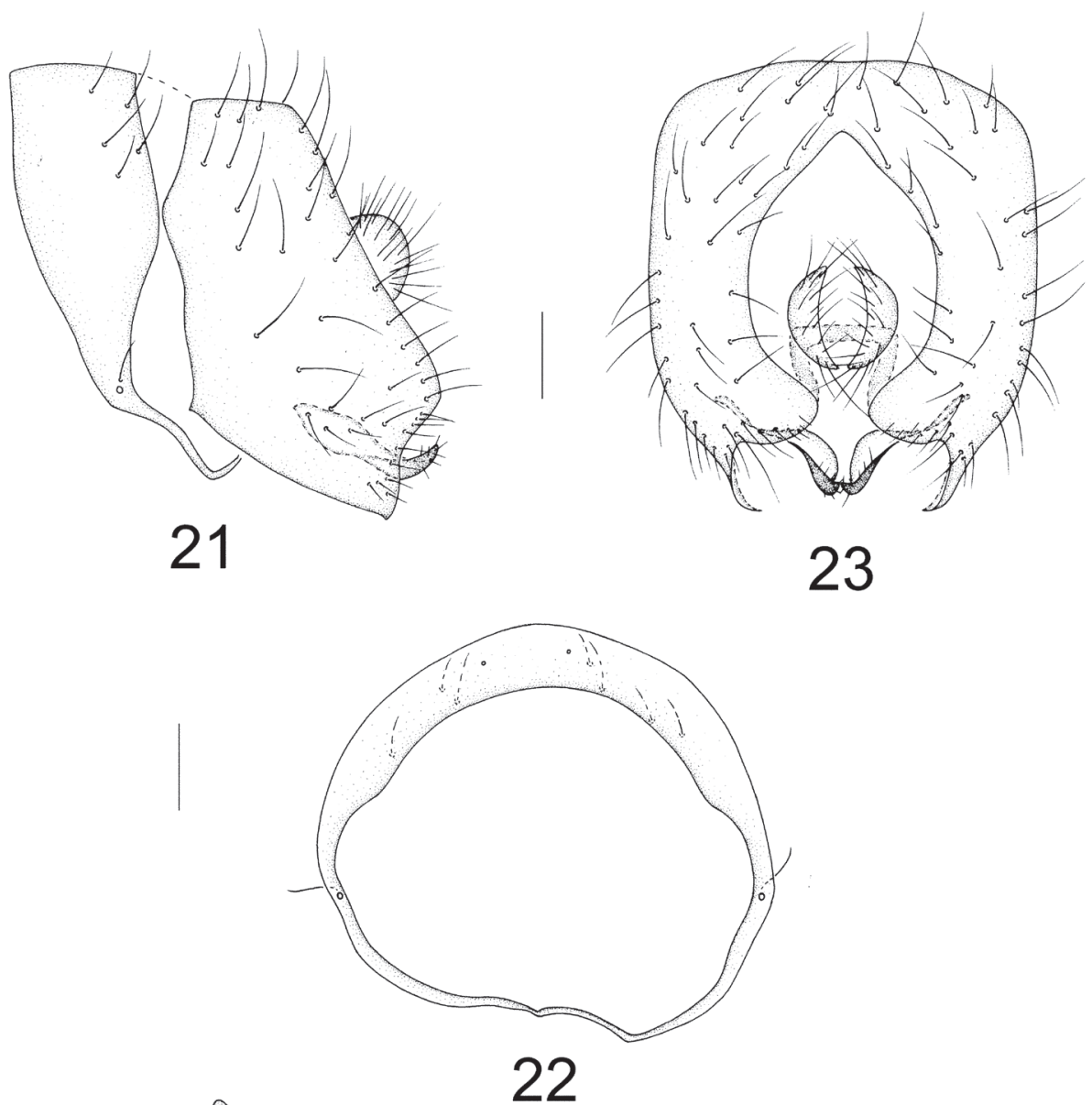
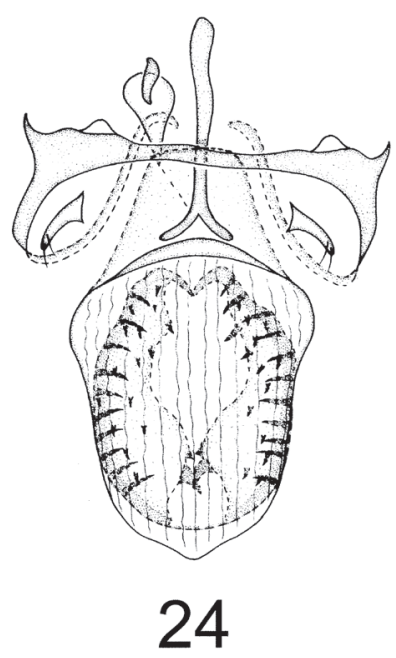

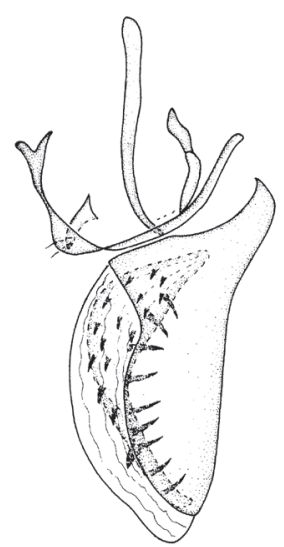

25

Figures 2I-25. Minettia (Minettiella) spinosa sp. n. Male. $2 \mathbf{I}$ syntergosternite and epandrium, lateral view 22 syntergosternite, anterior view $\mathbf{2 3}$ epandrial complex, posterior view $\mathbf{2 4}$ aedeagal complex, ventral view 25 aedeagal complex, lateral view. Scale bar $=0.1 \mathrm{~mm}$. 
Description. MALE. Body length 3.4-4.0 mm, wing length 3.9-4.4 mm. FEMALE. Body length 3.5-4.1 mm, wing length $4.3-4.6 \mathrm{~mm}$.

Head. Face with a yellow triangular median spot or only slightly yellow in center of face, and parafacial brown with dense whitish gray pruinosity. Frons with yellow anterior margin (sometimes with a wide yellow median stripe in a few of specimens). Gena about 1/6 eye height. Antenna yellow with pale brown on apical 2/3 of 1 st flagellomere, 1st flagellomere nearly 1.7 times longer than high; arista with microscopic setulae, longest rays shorter than 1/3 height of 1 st flagellomere. An indistinct brown spot present between eye and base of antenna. Proboscis black with dark yellow at apex and palpus black.

Thorax with sparse whitish gray pruinosity. Mesonotum $0+3 d c$ (anterior $d c$ far behind transverse scutal suture), acr in 6 rows; prsc slightly longer than 1 st postsutural $d c$. Scutellum with dense yellowish brown pruinosity. Legs: all tibiae dark yellow and tarsi dark yellow with tarsomeres 3-5 pale brown (apex of fore tibia pale brown in a few specimens). Fore femur with $5 p v$ and $8 p d$, fore tibia with 1 short preapical $a d$ and 1 short $a p v$. Mid femur with $3 a$ and $1 a p p$; mid tibia with 1 strong preapical $a d$ and 1 strong $a p v$. Hind femura with 1 weak preapical $a d$, hind tibia with 1 weak preapical $a d$ and 1 short apv. Wing slightly yellow with black at base; costa with 2nd (between $\mathrm{R}_{1}$ and $\mathrm{R}_{2+3}$ ), 3rd (between $\mathrm{R}_{2+3}$ and $\mathrm{R}_{4+5}$ ) and 4th (between $\mathrm{R}_{4+5}$ and $\mathrm{M}_{1}$ ) sections in proportion of 11:1.5:1;r-m at middle of discal cell; ultimate and penultimate sections of $\mathrm{M}_{1}$ in proportion of 1:1.2; ultimate section of $\mathrm{CuA}_{1}$ about $1 / 6$ of penultimate section.

Abdomen with sparse whitish gray pruinosity. Male genitalia (Figs 21-25): syntergosternite circular with a setula near spiracle, epandrium with a small subapical incision in lateral view and acute apically in posterior view, and surstylus contorting with apical setulae and originating from inner side of epandrium in lateral view; hypandrium slender, nearly $\mathrm{H}$-shaped and hypandrial apodeme indistinct; pregonite tiny, slightly curved with two setulae; aedeagus broad, with dorsal sclerite round apically, membranous parts beyond apex of dorsal sclerite with short spinules and a pair of long hook-like basal processes; aedeagal apodeme slender. Female terminalia (Figs 39-40): sternite 7 rectangular, slightly concave on prosterior margin, sternite 8 semicircular with a pair of processes on anterior margin and a wide groove between processes; spermathecae $2+1$, round.

Remarks. The new species is similar to M. (Minettiella) plurifurcata sp. n. from Hubei in the following characteristics: mesonotum $0+3 d c$, acr in 6 rows; fore femur with $5 p v$ and $8 p d$, but it can be separated from the latter in the epandrium having a small subapical incision in lateral view and acute apically in posterior view and the surstylus being contorting with apical setulae in lateral view. In M. (Minettiella) plurifurcata, the epandrium has a wide median incision on the dorsal margin in lateral view and the surstylus is short subuliform in lateral view and convergent apically in posterior view.

Distribution. China (Hubei). 


\section{Minettia (Minettiella) tianmushanensis sp. $\mathbf{n}$.} http://zoobank.org/9FE6AC20-3358-4C00-BBEC-98F53FCF9517 Figs 26-30, 41-43

Type materials. Holotype $\widehat{\partial}$ (CAUC), CHINA, Zhejiang: Lin'an, Tianmushan Na-

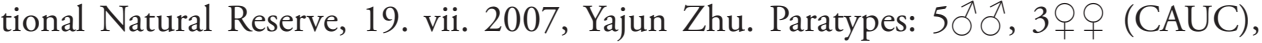

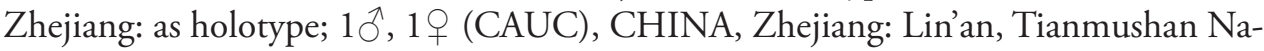
tional Natural Reserve, Dajinggu, 20. vii. 2007, Yajun Zhu.

Etymology. The new species is named after the type locality Tianmushan National Nature Reserve, Zhejiang Province

Diagnosis. Frons slightly upturned with yellow anterior margin and short brownish yellow median stripe. Antenna brown with 1st flagellomere yellow at base; arista pubescent, with longest rays about $1 / 3$ height of 1 st flagellomere. Mesonotum $0+2 d c$, acr in irregular 4 rows. Mid tarsi dark yellow and basitarsus with 1 subbasal $p v$, and hind tarsi dark yellow.

Description. MALE. Body length 3.4-3.7 mm, wing length 3.4-3.6 mm. FEMALE. Body length 3.2-3.5 mm, wing length 3.3-3.6 mm.

Head. Frons with yellow anterior margin, slightly upturned and short brownish yellow median stripe. Gena about 1/10 eye height. Antenna brown with 1st flagellomere yellow at base and 1st flagellomere nearly 1.8 times longer than high; arista pubescent, longest rays about $1 / 3$ height of 1 st flagellomere. Proboscis and palpus blackish brown.

Thorax with brownish gray pruinosity. Mesonotum with $0+2 d c$, acr in irregular 4 rows, a pair of long acr in front of prsc, prsc longer than 1st postsutural $d c$. Legs: tibia black, fore tarsi black, mid and hind tarsi dark yellow. Fore femur with 4-5 pv and $8 p d$, fore tibia with 1 long preapical $a d$ and 1 short apv. Mid femur with 3-4a and $1 a p p$; mid tibia with 1 strong preapical $a d$ and 1 strong $a p v$, mid basitarsus with 1 subbasal $p v$. Hind femur with 1 preapical $a d$, hind tibia with 1 weak preapical ad and 1 short apv. Wing with costa with 2nd (between $\mathrm{R}_{1}$ and $\mathrm{R}_{2+3}$ ), 3rd (between $\mathrm{R}_{2+3}$ and $\mathrm{R}_{4+5}$ ) and 4th (between $\mathrm{R}_{4+5}$ and $\mathrm{M}_{1}$ ) sections in proportion of 5:1:1; $r-m$ beyond middle of discal cell; ultimate and penultimate sections of $\mathrm{M}_{1}$ in proportion of 1:1.1; ultimate section of $\mathrm{CuA}_{1}$ about $1 / 6$ of penultimate section.

Abdomen with sparse brownish gray pruinosity. Male genitalia (Figs 26-30): syntergosternite circular; epandrium slender, nearly rhombic and narrow apically; surstylus separated from epandrium, contorted claviform in lateral view and subuliform in posterior view with two acute apical teeth; hypandrium nearly U-shaped in ventral view, hypandrial apodeme distinct; postgonite S-shaped with two apical setulae in lateral view; aedeagus subuliform, narrow apically with a small incision in ventral view and wide rectangular, slightly projecting subapically with a small acute apical process in lateral view; aedeagal apodeme long, as long as height of aedeagus. Female terminalia (Figs 41-43): ternite 7 concave in lateral view, tergite 8 constricted medially; sternite 9 semicircular, sternite 8 slender, sternite 7 concave apically with a pair of triangular apical processes, curved outward; spermathecae $2+1$, elliptical. 

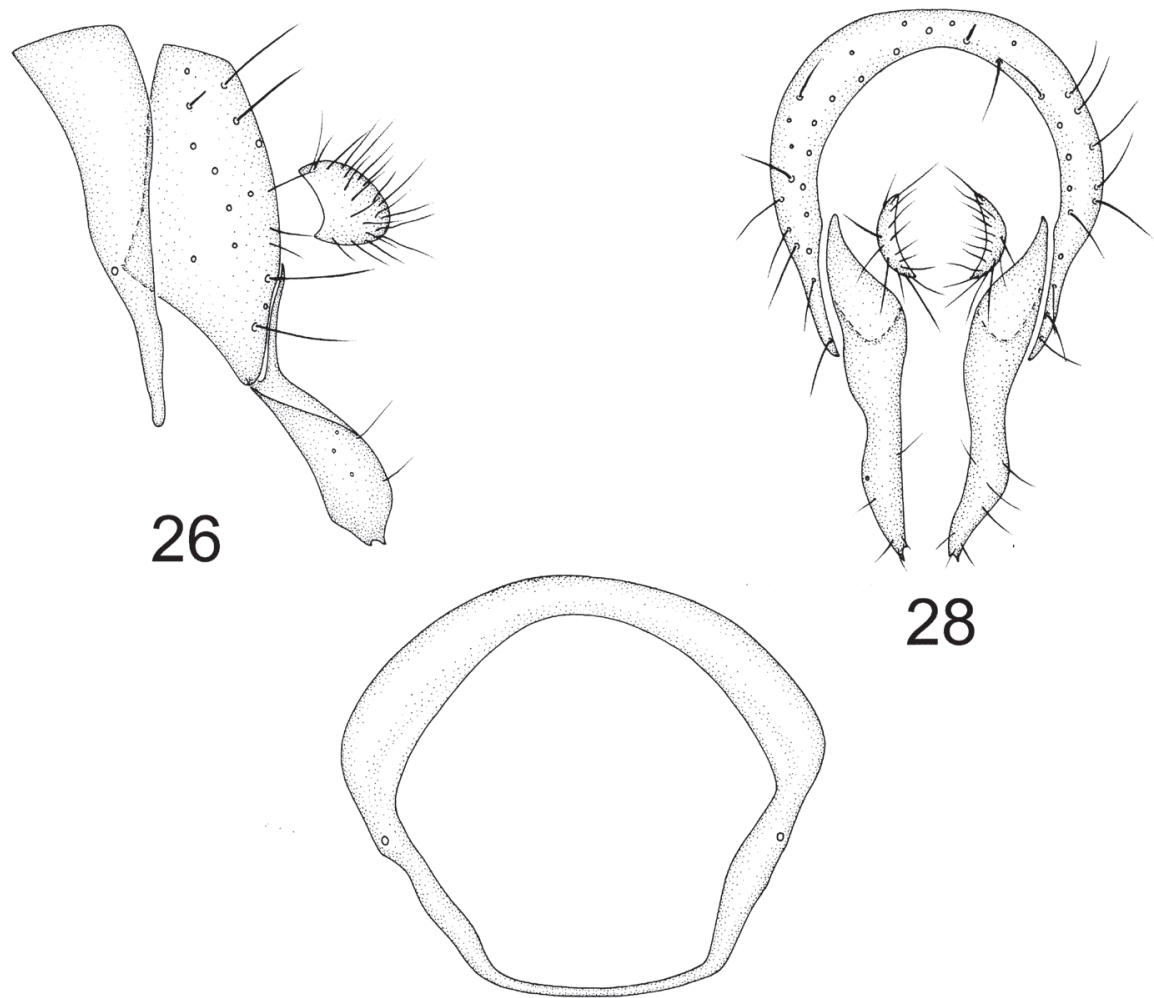

28

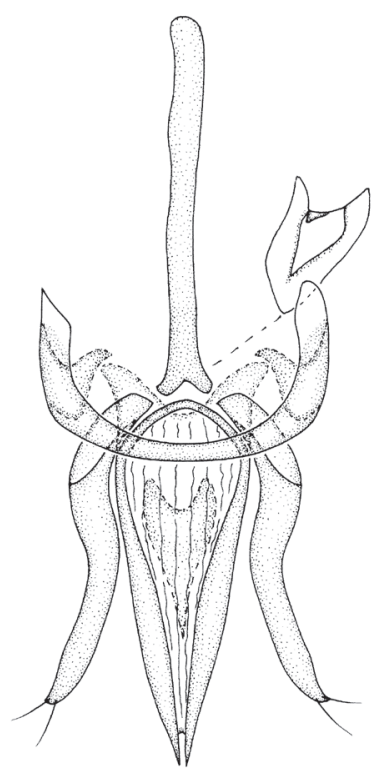

29

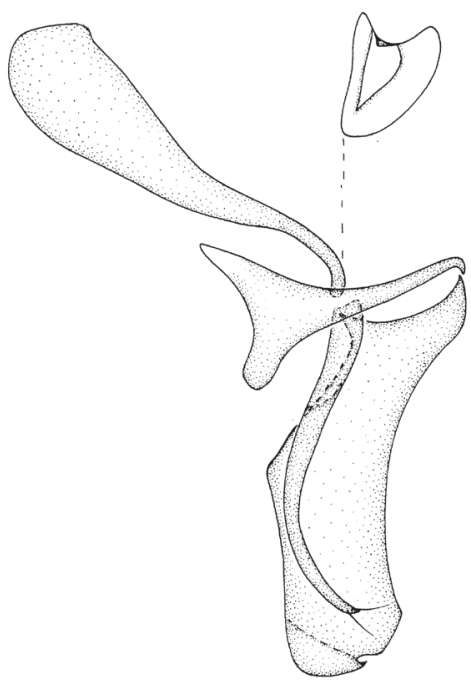

30

Figures 26-30. Minettia (Minettiella) tianmushanensis sp. n. Male. 26 syntergosternite and epandrium, lateral view $\mathbf{2 7}$ syntergosternite, anterior view $\mathbf{2 8}$ epandrial complex, posterior view $\mathbf{2 9}$ aedeagal complex, ventral view $\mathbf{3 0}$ aedeagal complex, lateral view. Scale bar $=0.1 \mathrm{~mm}$. 

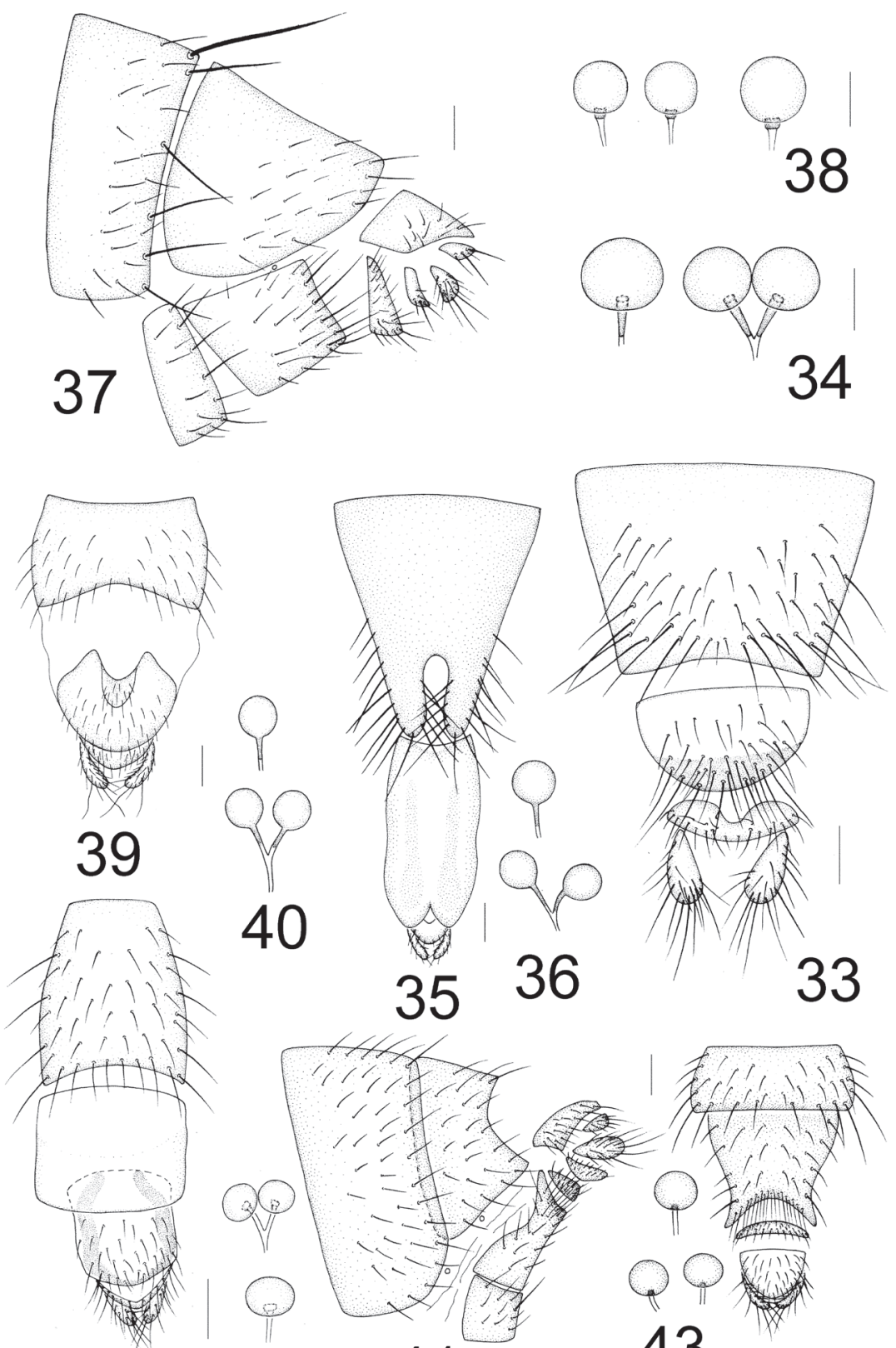

33
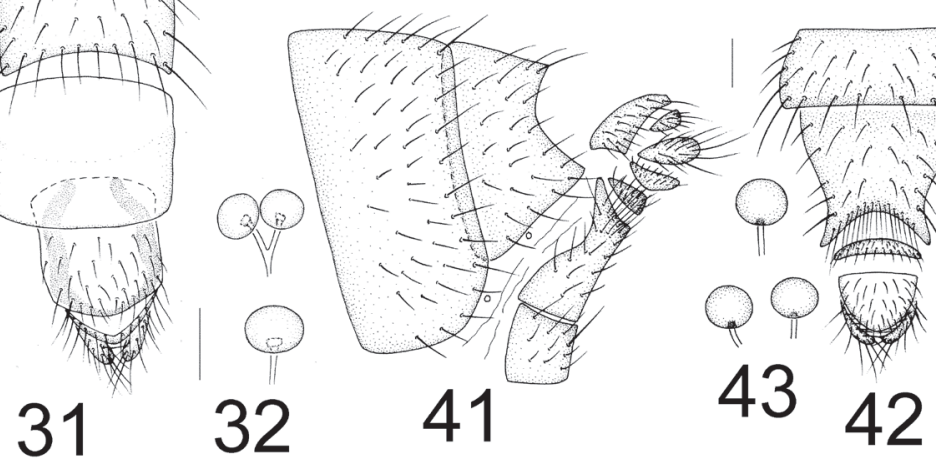

Figures 31-43. Female terminalia. Minettia (Minettiella) atratula (Meijere, 1924). 31 sternites 7-9, ventral view 32 spermathecae. Minettia (Minettiella) bawanglingensis sp. n. 33 sternites 7-9, ventral view 34 spermathecae. Minettia (Minettiella) clavata sp. n. 35 sternites 7-9, ventral view 36 spermathecae. Minettia (Minettiella) sasakawai Shi, Wang \& Yang, 2011. 37 tergites and sternites 6-9, lateral view 38 spermathecae. Minettia (Minettiella) spinosa sp. n. 39 sternites 7-9, ventral view 40 spermathecae. Minettia (Minettiella) tianmushanensis sp. n. 4I tergites and sternites 6-9, lateral view 42 sternites 6-9, ventral view 43 spermathecae. Scale bar $=0.1 \mathrm{~mm}$. 
Remarks. The new species is very similar to $M$. (Minettiella) sasakawai from China (Hainan) and Vietnam in the following characteristics: mesonotum with $0+2 d c, a c r$ in 4 rows, and a pair of long acr present in front of prsc; wing pale yellow at base, but it can be separated from the latter in the syntergosternite being circular, the surstylus being contorting and claviform in lateral view and subuliform in posterior view with two acute apical teeth, and the female abdominal tergite 6 having no long dorsal setae on the posterior margin. In M. (Minettiella) sasakawai, the syntergosternite is semicircular and narrow under the spiracle; the surstylus is slender, narrow apically with a falcate apical process in lateral view and the female abdominal tergite 6 has a pair of long dorsal setae on the posterior margin.

Distribution. China (Zhejiang).

\section{Key to the subgenera of Minettia and the species of the subgenus Minettiella}

Frons shining and face flat; arista pubescent; mesonotum with $0-1+2-3 d c$ and $0-1+2-4$ long acr; katepisternum with 1 strong kepst; male genitalia: dorsal aedeagal sclerite present subgenus Minettiella Malloch...6

- $\quad$ Frons often dull and face slightly concave; arista pubescent or plumose; mesonotum with $0+3 d c$ and $0+2-3$ long acr; katepisternum with 1 strong and 1 weak kepst; male genitalia: dorsal aedeagal sclerite absent (if dorsal aedeagal sclerite present, but no presutural $d c$ )..... Lower part of face with a distinct, slight and weakly round swelling on each side

- $\quad$ Lower part of face without round swelling on each side. Basal part of wing black; arista long plumose, with longest rays longer than height of 1st flagellomere (rarely shorter than height of 1st flagellomere); male genitalia: ventral hypandrial appendages represented by two pairs of sclerites (including some Palaearctic and Oriental species). subgenus Frendelia Collin

- $\quad$ Basal part of wing yellow; arista short plumose, with longest rays as long as 1/2 height of 1 st flagellomere; male genitalia: ventral hypandrial appendages represented by one pair of sclerites (such as M. eoa Shatalkin, 1992).

part of subgenus Scotominettia Shatalkin

Male genitalia: ventral hypandrial appendages represented by one pair of sclerites; arista short plumose, with longest rays as long as $1 / 2$ height of 1 st flagellomere (such as Minettia austriaca Hennig, 1951).

\section{part of subgenus Scotominettia Shatalkin}

Male genitalia: hypandrial appendages without representing by one pair of sclerites, often transverse bar-like, U-shaped or other shapes; arista plumose or pubescent 
$5 \quad$ Arista with fine microscopic setulae, with longest rays as long as or shorter than 1/4 height of 1st flagellomere (rarely bare); wing yellow at base; male genitalia: aedeagal dorsal sclerite absent; postgonites fused dorsally forming a hood for aedeagus ................................subgenus Plesiominettia Shatalkin

- $\quad$ Arista short to long plumose with longest rays longer than $1 / 3$ height of 1 st flagellomere; wing yellow or brown at base; male genitalia: aedeagal dorsal sclerite present (square, rectangular, triangular and trapeziform); postgonites separate subgenus Minettia Robineau-Desvoidy

Mesonotum with $1+3 d c$, acr in 2 rows, $1+3$ long acr; male genitalia: epandrium narrow basally and broad apically, with a deep concavity on anterior ventral margin and a digitiform anterior process, triangular apically in lateral view; surstylus elliptical in lateral view (Figs 31-32)

Minettia (Minettiella) atratula

- Mesonotum lacking a presutural $d c$, acr in 2-6 rows, without long acr; male genitalia: epandrium without deep concavity on anterior ventral margin and a digitiform anterior process in lateral view; surstylus not elliptical in lateral

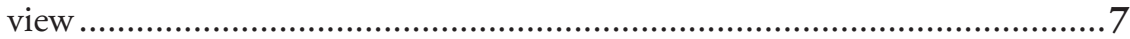

Mesonotum with $0+3 d c$ (exceptionally $M$. (Minettiella) dolabriforma rarely with $0+3 d c$, anteriormost $d c$ is considerably smaller than usual, only half length of the second $d c$ )

Mesonotum with acr in 6 rows (exceptionally $M$. (Minettiella) dolabriforma rarely with acr in 6 rows, a pair of acr long, just behind level of anterior $d c$ and about two third length of prsc)....

acr with two pairs of strong setae in front of one pair of prsc in dorsal view; arista pubescent, with longest rays about $1 / 4$ height of 1 st flagellomere; mid and hind tarsi yellow..... Minettia (Minettiella) bawanglingensis sp. $\mathbf{n}$. acr with a pair of strong setae in front of one pair of prsc in dorsal view; arista plumose; only hind tarsi yellow. Minettia (Minettiella) atrata

10 Arista with microscopic setulae; male genitalia: surstylus narrow apically with a falcate apical process in lateral view ...... Minettia (Minettiella) sasakawai - $\quad$ Arista pubescent, with longest rays about $1 / 3$ height of 1 st flagellomere; male genitalia: surstylus wide apically with teeth or acute process in lateral view .... 11

11 Female sternite 9 rectangular, about three times as wide as long, and sternite 7 without triangular apical processes; male genitalia: surstylus with an acute process projecting forwards in lateral view. Minettia (Minettiella) dolabriforma Female sternite 9 semicircular, sternite 7 with a pair of triangular apical processes (Figs 41, 42); male genitalia: surstylus contorted claviform in lateral view and subuliform in posterior view, with two acute apical teeth (Figs $26,28)$ Minettia (Minettiella) tianmushanensis sp. $\mathbf{n}$. 


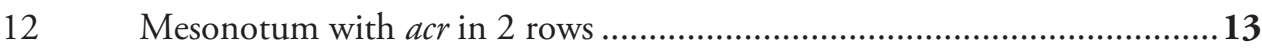

- Mesonotum with acr in 6 rows ............................................................14

13 Anepisternum with bluish grey pruinosity; mid and hind tibiae yellow.

Minettia (Minettiella) acrostichalis

- $\quad$ Anepisternum with whitish grey pruinosity; mid and hind tibiae yellow except blackish apical 1/4............................ Minettia (Minettiella) coracina

14 Mesonotum with brownish grey pruinosity, 1st postsutural $d c$ weak, hairlike, prsc longer than 1st postsutural $d c$, male genitalia: surstylus fused with the epandrium, claviform with a triangular basal process, a projecting apical process, a small acute ventroapical process and a tiny incision in lateral view (Figs 11, 13) Minettia (Minettiella) clavata sp. n.

- $\quad$ Mesonotum with whitish grey pruinosity, 1 st postsutural $d c$ strong, prsc as long as or longer than 1 st postsutural $d c$; male genitalia: surstylus articulated with epandrium, triangular or lobe-like with a single process .....................15

15 Face and parafacial with sparse whitish gray pruinosity; arista short plumose, longest rays slightly shorter than height of 1 st flagellomere; mid femur with $4 a$; male genitalia: epandrium with a wide median incision on dorsal margin in lateral view; surstylus short subuliform and originating from inner side of epandrium in lateral view and converging apically in posterior view (Figs 16, 18); female unknown.................. Minettia (Minettiella) plurifurcata sp. $\mathbf{n}$.

- $\quad$ Face with a yellow triangular median spot or only slightly yellow at middle of face, and parafacial with dense whitish gray pruinosity; arista with microscopic setulae, longest rays shorter than $1 / 3$ height of 1 st flagellomere; mid femur with $3 a$; male genitalia: epandrium with a small subapical incision in lateral view and acute apically in posterior view, surstylus contorted with apical setulae and originating from inner side of epandrium in lateral view (Figs 21, 23); female sternite 8 semicircular with a pair of processes on anterior margin and a wide groove between processes (Fig 39)

Minettia (Minettiella) spinosa sp. n.

\section{Acknowledgments}

Li Shi gives sincere thanks to Stephen D. Gaimari (CDFA, Sacramento) for checking a few of specimens in USNM, providing literature, reviewing and giving kind comments to the manuscript, Anatole I. Shatalkin (Moscow, Russia) for providing and translating Russian literature, Tatiana Galinskaya (Moscow, Russia) for helping me to take photos of type specimens and Andrey Ozerov (Moscow, Russia) for giving me kind assistance during my visit in Moscow, László Papp for his reviewing the manuscript and giving good advice. This study is supported by a grant (No. 31260525) from the National Natural Science Fundation of China. 


\section{References}

Collin JE (1948) A short synopsis of the British Sapromyzidae (Diptera). Transactions of the Royal Entomological Society of London 99: 225-242. doi: 10.1111/j.1365-2311.1948. tb01236.x

Gaimari SD, Silva VC (2010) Lauxaniidae (Lauxaniid flies). In: Brown BV, Borkent A, Cumming JM, Wood DM, Woodley NE (Coords) Manual of Central American Diptera, Vol. 2. NRC Research Press, Ottawa, Ontario, Canada, 971-995.

Hennig W (1951) Neue Acalyptraten aus Europa und Sudafrika (Diptera: Piophilidae, Helomyzidae, Lauxaniidae). Beitraege zur Entomologie I: 70-76.

Jong Hde (2000) The types of Diptera described by J.C.H.DE Meijere. Backhuys publishers, Leiden, The Netherlands, $271 \mathrm{pp}$.

Malloch JR (1929) Notes on some Oriental Sapromyzid flies (Diptera), with particular reference to the Philippine species. Proceedings of the United States National Museum 74(6): 1-97. doi: 10.5479/si.00963801.74-2751.1

McAlpine JF (1981) Chapter 2. Morphology and Terminology: Adults. In: McAlpine JF, Peterson BV, Shewell GE, Teskey HJ, Vockeroth JR, Wood DM (Coords) Manual of Nearctic Diptera, Vol. 1. Research Branch, Agriculture Canada, Ottawa, Monograph 27: 9-63.

Meijere JCHde (1910) Studien über südostasiatische Diperen. IV. Die neue Dipteren-fauna van Krakatau. Tijdschrift voor Entomologie 53: 120-194.

Meijere JCHde (1924) Studien über südostasiatische Diperen. XV. Dritter Beitrag zur Kenntnis der sumatranischen Dipteren. Tijdschrift voor Entomologie (supplement) 67: 1-87.

Papp L, Shatalkin AI (1998) Family Lauxaniidae. In: Papp L, Darvas B. Contributions to a Manual of Palaearctic Diptera. Volume 3, Higher Brachycera. Science Herald, Budapest, 383-400.

Robineau-Desvoidy JB (1830) Essai sur les myodaires. Mémoires Présentés par divers Savants a l'Academie Royale des Sciences de de l'Institut de France 2(2): 813 pp.

Sasakawa M (2001) Oriental Lauxaniidae (Diptera) part 2. Fauna of the Lauxaniidae of Vietnam. Scientific Reports of Kyoto Prefectural University Human Enviroment and Agriculture 53: 39-94.

Sasakawa M, Mitsui H (1995) New lauxaniid and clusiid flies (Diptera) captured by bait-traps. Japanese Journal of Entomology 63(3): 515-521.

Sasakawa M, Kozánek M (1995) Lauxaniidae (Diptera) of Nortth Korea, part 2. Japanese Journal of Entomology 63(2): 323-332.

Shatalkin AI (1992) New lauxaniid flies (Diptera, Lauxaniidae) from the Amur Region and the Far East. Zoologicheskiy zhurnal 71(9): 79-87. [in Russian; English translation in: (1993) Entomological Review 72(1): 150-158.]

Shatalkin AI (1993) New and little-known Palaearctic Diptera of the families Platypezidae, Psilidae, and Lauxaniidae. Russian Entomological Journal (1992) 1(2): 59-74.

Shatalkin AI (1996) New and little known species of flies of Lauxaniidae and Strongylophthalmyiidae (Diptera). Russian Entomological Journal (1995) 4(1-4): 145-157.

Shatalkin AI (2000) Keys to the Palaearctic flies of the family Lauxaniidae (Diptera). Zoologicheskie Issledovania 5: 1-102. 
Shewell GE (1977) Family Lauxaniidae. In: Delfinado MD, Hardy DE. A catalogue of the Diptera of the Oriental Region. Volume III. Suborder Cyclorrhapha (excluding division Aschiza). The University Press of Hawaii, Honolulu, 182-214.

Shatalkin AI (2008) New and little known Palaearctic species of flies of Lauxaniidae (Diptera). Bulletin of the Moscow Society of Nature: Department of Biology 113(3): 55-60. [in Russian]

Shi L, Wang JC, Yang D (2011) Six homonymous species of three genera Homoneura, Minettia and Sapromyza (Diptera, Lauxaniidae). Acta Zootaxonomica Sinica 36(1): 80-83.

Stuckenberg BR (1971) A review of the Old World genera of Lauxaniidae (Diptera). Annals of the Natal Museum 20: 499-610.

\section{Appendix}

Genus Minettia Robineau-Desvoidy, 1830

Subgenus Minettiella Malloch, 1929

1. Minettia (Minettiella) acrostichalis (Sasakawa \& Kozánek, 1995) (Calliopum). Oriental: North Korea.

2. Minettia (Minettiella) atrata (Meijere, 1910) (Lauxania). Oriental: Indonesia, Malaysia.

3. Minettia (Minettiella) atratula (Meijere, 1924) (Lauxania). Oriental: China (Taiwan, Hainan), Indonesia, Vietnam.

4. Minettia (Minettiella) bawanglingensis sp. n. Oriental: China (Hainan).

5. Minettia (Minettiella) clavata sp. n. Oriental: China (Hubei).

6. Minettia (Minettiella) coracina Shatalkin, 1993. Palaearctic: Russia.

7. Minettia (Minettiella) dolabriforma (Sasakawa \& Kozánek, 1995) (Calliopum). Palaearctic: North Korea, Japan, Russia.

Minettia japonica Sasakawa, in Sasakawa \& Mitsui, 1995. Syn. n. Minettiella elbergi Shatalkin, 1996. Syn. n.

8. Minettia (Minettiella) plurifurcata sp. n. Oriental: China (Hubei).

9. Minettia (Minettiella) spinosa sp. n. Oriental: China (Hubei).

10. Minettia (Minettiella) sasakawai Shi, Wang \& Yang, 2011. Oriental: China (Hainan), Vietnam.

Sapromyza acrostichalis Sasakawa, 2001 .[Homonym of Calliopum acrostichalis Sasakawa \& Kozánek, 1995, when in Minettia]

11. Minettia (Minettiella) tianmushanensis sp. n. Oriental: China (Zhejiang). 